\title{
UTILIZAÇÃO DAS GEOTECNOLOGIAS NA IDENTIFICAÇÃO DOS NÍVEIS DE DEGRADAÇÃO DA MICROBACIA HIDROGRÁFICA CÓRREGO IPÊ, GUARAÇAI - SP
}

\author{
Douglas Teixeira Campos ${ }^{1}$
}

Thiago Lopes e Silva ${ }^{2}$

\section{Arthur Pantoja Marques ${ }^{3}$}

RESUMO: Em geotecnologias são utilizadas técnicas de geoprocessamento para delimitação dos divisores de água das sub-bacias hidrográficas, vetorização da rede de drenagem e avaliação do nível de degradação das Áreas de Preservação Permanentes. Além de técnicas de georreferenciamento para o refinamento do registro das imagens fusionadas e para verificação dos dados obtidos em campo e análises de caracterização fisiográficas. No presente trabalho, foi possível identificar niveis de degradação da microbacia hidrográfica Córrego do Ipê localizado no município de Guaçarai SP, e a partir das análises fisiográficas, os quais demonstraram que a microbacia em estudo apresenta dificuldades em escoar a água precipitada, devido ao seu formato que tende a ser circular segundo Muller (1953) e Schumm (1956). Verificou-se também que a área de estudo está pouco sujeita a processos de inundação e também foi classificada segundo a classificação de Strahler (1957) como sendo de $4^{a}$ ordem. Apesar destas conclusões

\footnotetext{
${ }^{1}$ Acadêmico do Curso de Agronomia, Faculdade de Engenharia de llha Solteira/UNESP, E-mail: douglastcampos@hotmail.com

${ }^{2}$ Mestrando do Curso de Engenharia Civil, Faculdade de Engenharia de Ilha Solteira/UNESP, E-mail: thiagolopesesilva@gmail.com

${ }^{3}$ Docente do Curso de Engenharia Civil, Faculdade de Engenharia de llha Solteira/UNESP, E-mail: artur@dec.feis.unesp.br
} 
a bacia apresenta alto grau de degradação, resultado de anos de interferência humana e uso de técnicas inadequadas.

\section{INTRODUÇÃO}

O mal uso de áreas acabam gerando grandes problemas ambientais, dos quais podemos citar a degradação de Áreas de Preservação Permanente $\left(\mathrm{APP}_{\mathrm{s}}\right)$, que mesmo com rígidas normas impostas pelos governos, são frequentemente agravadas. Uma análise correta desses níveis de degradação necessita de uma ampla visão, ou seja, varias áreas de atuação envolvidas. O geoprocessamento é uma ótima ferramenta para análise dessas áreas com degradação, pois possui muitas ferramentas que podem gerar dados e tabelas os quais com apoio da literatura podem levar a inferências sobre os níveis de degradação dessas $\mathrm{APP}_{\mathrm{s}}$.

Segundo CÂMARA \& MEDEIROS (1998), o termo geoprocessamento é uma tecnologia que utiliza técnicas matemáticas e computacionais para tratar as informações geográficas. Essa tecnologia constitui-se em técnicas fundamentais para a manutenção de registros atualizados do uso da terra e dos corpos d'água. As imagens de satélites, associadas aos Sistemas de Informações geográficas (SIG), constituem fontes essenciais para obtenção de informações do dinamismo do meio físico frente às atividades antrópicas.

Para o monitoramento da dinâmica do uso da terra é fundamental a utilização de sistemas de alta capacidade para tratamento e análise de informações multitemáticas como são as técnicas de Sensoriamento Remoto e de Geoprocessamento. A interpretação visual das imagens de satélites como o CBERS (China-Brazil Earth Resources Satellite) é o processo de obtenção de informações sobre um dado alvo da superfície, através da análise de elementos de reconhecimento como tonalidade, textura, forma, padrão, tamanho, sombra e localização. Esse processo consiste basicamente na inspeção e identificação desses diferentes elementos de reconhecimento em cada banda espectral, assim como sua comparação em diferentes bandas. 


\section{REVISÃO BIBLIOGRÁFICA}

\subsection{Vegetação e matas ciliares}

As matas ciliares funcionam como filtros, retendo defensivos agrícolas, poluentes e sedimentos que seriam transportados para os cursos d'água, afetando diretamente a quantidade e qualidade da água e conseqüentemente a fauna aquática e a população humana. São importantes também como corredores ecológicos, ligando fragmentos florestais e, portanto, facilitando o deslocamento da fauna e o fluxo gênico entre populações de espécies animais e vegetais. Em regiões com topografia acidentada, exercem a proteção do solo contra os processos erosivos (MARTINS, 2001).

A delimitação das Áreas de Preservação Permanentes $\left(\mathrm{APP}_{\mathrm{S}}\right)$ representa uma das ações mais importantes envolvidas no processo de adequação ambiental, considerando a importância ecológica dessas áreas. A preservação da vegetação natural nas margens dos rios e ao redor das nascentes e reservatórios são regulamentados pela lei desde 1965 (lei n 4.771), quando foi instituído o Código Florestal (DURIGAN et al., 2001).

Já a Medida Provisória no 2.166-67, de 24/08/2001 define como Áreas de Preservação Permanente: áreas cobertas ou não por vegetação nativa, com a função ambiental de preservar os recursos hídricos, a paisagem, a estabilidade geológica, a biodiversidade, o fluxo gênico de fauna e flora, proteger o solo e assegurar o bem-estar das populações humanas.

\subsection{Redes de Drenagem}

A rede de drenagem de uma região geográfica define os caminhos de escoamento de líquidos, normalmente água de chuva, de acordo com o relevo da região. A informação por ela gerada é usada em atividades diversas, tais como: estudo de relevo, determinação de áreas com risco de erosão do solo, transporte de poluentes, delimitação de áreas inundadas e estudo de bacias hidrográficas. (ROSIM \& PELLEGRINO, 1999)

O deflúvio de uma bacia hidrográfica resulta de fluxos líquidos superficiais e subsuperficiais (RESENDE et al., 1995) 
Com o crescente uso da água para diversos fins, e o estado de degradação em que se encontram os mananciais, é necessário administrar sua disponibilidade e uso, além do conhecimento atualizado do quadro degradante quando houver e criar processos de gerenciamento para sua recuperação e/ou conservação, assegurando desta maneira a qualidade e quantidade dos recursos que esta pode oferecer (BORSATO, 2004).

\subsection{Sistemas de informações geográficas (SIG)}

CÂMARA et al. (2005) comentam que o termo Sistemas de Infomação Geográfica é aplicado para sistemas que realizam o tratamento computacional de dados geográficos e recuperam informações não apenas com base em suas características alfanuméricas, mas também através de sua localização espacial; oferecem ao administrador (urbanista, planejador, engenheiro) uma visão inédita de seu ambiente de trabalho, em que todas as informações disponíveis sobre determinado assunto estão ao seu alcance, interrelacionadas com base no que thes é fundamentalmente comum; a localização geográfica. Para que isso seja possível, a geometria e os atributos dos dados num SIG devem estar georreferenciados, isso é, localizados na superfície terrestre e representados numa projeção cartográfica. Assim o georreferenciamento tem como objetivo associar coordenadas de imagens (linha e colunas) às de um sistema de referência (RICHARDS, 1993).

\subsection{Sensoriamento Remoto}

Para MORAES (1999) pode-se entender sensoriamento remoto como formas de obtenção de dados sobre um objeto, terreno, espécime, etc, sem contato físico com o mesmo.

Já segundo FLORENZANO (2002), sensoriamento remoto é a tecnologia que permite obter imagens e outros tipos de dados da superfície terrestre, através da captação e do registro da energia refletida ou emitida pela superfície. $O$ termo sensoriamento refere-se à obtenção dos dados e remoto, que significa distante, é utilizado 
porque a obtenção é feita à distância, ou seja, sem o contato físico entre o sensor e a superfície terrestre.

\subsection{Geoprocessamento}

As geotecnologias estão em um estágio que permite fazer uma análise espacial que combine o mapeamento dos problemas urbanos com informações físicas, demográficas, geográficas, topográficas ou de infra-estrutura, auxiliando assim na adoção de soluções para diversos problemas de uma forma mais racional e rápida (CORDOVEZ, 2002).

O Geoprocessamento é um conjunto de tecnologias de coleta de informações, de desenvolvimento e uso de sistemas que as utilizam, envolvendo atividades como sensoriamento remoto, modelagem numérica de terreno, processamento de imagens e outras atividades de captura de dados (RODRIGUES, 1990).

Para Câmara e Medeiros (1998), o termo Geoprocessamento é definido como uma disciplina do conhecimento que utiliza técnicas matemáticas e computacionais para o tratamento de informações geográficas, observadas pelos sensores.

\section{MATERIAL E MÉTODOS}

\subsection{Caracterização da Área de Estudo}

O município de Guaraçaí localiza-se na região noroeste do Estado de São Paulo na província geomorfológica do Planalto Ocidental Paulista. Integrante da região administrativa de Araçatuba, com uma extensão territorial de 568 km². Guaraçaí limita-se ao norte com o rio Tietê e ao Sul com o rio Aguapeí, integrando duas importantes Unidades de Gerenciamento de Recursos Hídricos do oeste paulista: Bacia Hidrográfica do Baixo Tietê e Bacia Hidrográfica do rio Aguapeí. A microbacia hidrográfica Córrego do Ipê, esta localizada na porção central do município possuindo uma área de 27,41 km2 
sendo ocupada principalmente pela cultura da cana de açúcar, pastagem e vegetação natural.

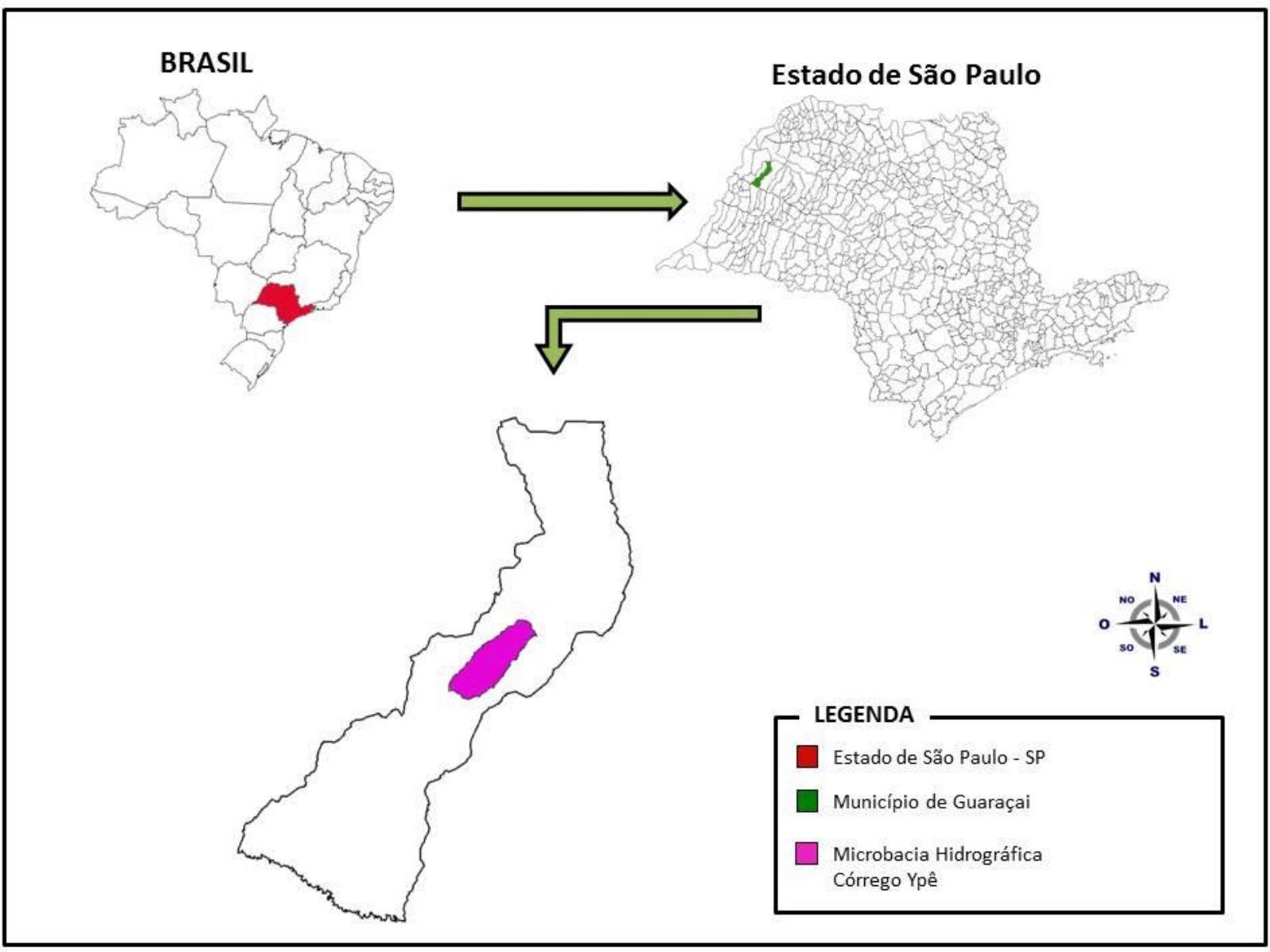

Figura 1. Localização da área de estudo microbacia

\subsection{Metodologia}

Foi obtida a imagem ortorretificada do LANDSAT 7, sensor ETM+, órbita/ponto 222/75 do dia 28 de abril de 2006 disponibilizada no site do Global Land Coveracility(http://glcf.umiacs.umd.edu/data/landsat/). Esta imagem foi utilizada para 0 georreferenciamento da imagem atualizada do satélite CBERS-2B, sensores CCD e HRC que cobre a microbacia hidrográfica. Foi utilizada a imagem orbital do satélite CBERS-2B, sensor CCD com resolução espacial de 20 metros e sensor HRC com resolução de 2,5 metros, obtidas através do site do Instituto Nacional de Pesquisas Espaciais - INPE (http://www.inpe.br) acessado no dia 13 de julho de 2010. As imagens orbitais da câmera 
de média resolução, CCD, utilizada foi a orbitas/pontos 159/124 do dia 27/09/2009. Em relação às imagens de alta resolução do sensor HRC, também disponibilizadas no mesmo site do INPE, foram obtidas quatro imagens das seguintes orbitas/pontos: 159_A/124_1 do dia 27 de setembro de 2009, 159_A/124_2 do dia 27 de setembro de 2009, 159_B/124_1 do dia 05 de outubro de 2009, 159_A/124_5 do dia 27 de setembro de 2009. Para o desenvolvimento do trabalho foi utilizado o software de domínio público SPRING (Sistema de Informações Georreferenciadas) na versão 5.2.1, desenvolvido pelo INPE. Inicialmente foi criado o Banco de Dados denominado Córrego Ipê, dentro deste Banco de Dados foi criado o projeto também denominado Córrego Ipê.

Foi adotada a projeção Universal Transverse Mercator (UTM) e datum de referência SIRGAS2000. O passo seguinte foi a importação da imagem ortorretificada do satélite LANDSAT para o projeto Córrego Ipê Na etapa seguinte, foi realizada a operação de registro da imagem CCD/CBERS tomando como referência a imagem LANDSAT 7/ETM+ ortorretificada.

Em seguida foi realizada a técnica de restauração da imagem CCD/CBERS. Posteriormente utilizando como referência a imagem CCD/CBERS foi efetuado o registro das imagens CBERS, sensor HRC. Como cada imagem do sensor HRC cobre uma área $1 / 25$ da imagem CCD, inicialmente foi realizado o processo denominado Reamostragem. Após essa etapa foi utilizada a técnicas de fusão Intensidade-Matiz-Saturação (IHS).

Em seguida foi gerado o mosaico das imagens HRC fusionadas. Finalmente foi realizado um refinamento no georreferenciamento dessas imagens utilizando 30 pontos de controle coletados em campo através de um conjunto GPS Geodésico modelo SYSTEM 1200 - RTK da marca LEICA. Esta etapa teve como finalidade a conferência de pontos de apoio (georreferenciados) para fornecer controle às imagens orbitais usadas no projeto. A metodologia utilizada seguiu as normas técnicas oficiais vigentes NBR/ABNT 13.133/94, LEI 10267/INCRA.

$\mathrm{Na}$ etapa seguinte foi realizada a vetorização da rede de drenagem e do divisor de água da microbacia. Após a identificação dos canais de drenagem, foi utilizada a ferramenta Edição Vetorial para traçar as linhas que representam os seguintes dados da rede de drenagem: leito seco e canal perene. Em seguida foram identificadas e digitalizadas as nascentes. Nas regiões da microbacia onde os canais de drenagem eram 
muito estreitos e não possuíam áreas úmidas, a rede de drenagem foi digitalizada através do Método das Crênulas (BIASI, 1970) que utiliza as inflexões das curvas de nível presentes nas cartas do IGGSP registradas e com o auxílio das imagens de alta resolução espacial disponíveis no Google Earth. Na etapa seguinte foi realizada a hierarquização de toda a rede de drenagem da bacia hidrográfica, utilizando o método proposto por Strahler (1964).

A avaliação da acurácia do divisor de água foi realizada através de coleta de pontos obtidos em campo com GPS geodésico e a das nascentes foi verificada através de trabalhos de campo em 9 das nascentes distribuídas aleatoriamente correspondente a uma amostra representativa do total de 87 nascentes existentes na bacia hidrográfica.

O processo de caracterização fisiográfica consiste na determinação de uma série de fatores como: área de drenagem, fator de forma, coeficiente de compacidade, sistema de drenagem, ordem dos canais, densidade de drenagem, extensão média do escoamento superficial. Moura (2008) afirma que o processo de caracterização fisiográfica em bacias é essencial para a elaboração e implementação de futuros projetos, pois, os resultados auxiliam na compreensão do escoamento superficial de uma bacia hidrográfica.

O fator área de drenagem segundo Andrade et al. (2008) compreende à medida em projeção horizontal, em que, é considerada toda a área da bacia hidrográfica. Normalmente seus resultados são expressos em $\mathrm{km}^{2}$.

Para a determinação do formato da bacia, é necessária a obtenção de dois outros fatores: Coeficiente de compacidade $(\mathrm{Kc})$ esse fator relaciona o perímetro de uma bacia e a circunferência de área igual presente na respectiva bacia, quanto mais irregular a forma da bacia hidrográfica, maior será esse índice (Carvalho et al., 2009). Seu cálculo utiliza a seguinte expressão:

$$
K c=0,28 \cdot \frac{P}{\sqrt{A}}
$$

Onde: $\mathrm{Kc}=$ coeficiente de compacidade (adimensional); $\mathrm{P}=$ perímetro $(\mathrm{km}) ; \mathrm{A}=$ área $\left(\mathrm{km}^{2}\right)$; O Fator Forma $(\mathrm{Kf})$ é determinado através da razão entre a largura média da bacia e o comprimento axial da mesma. Andrade et al. (2008) complementam que esse fator é obtido com a medição do comprimento desde a desembocadura até a cabeceira da 


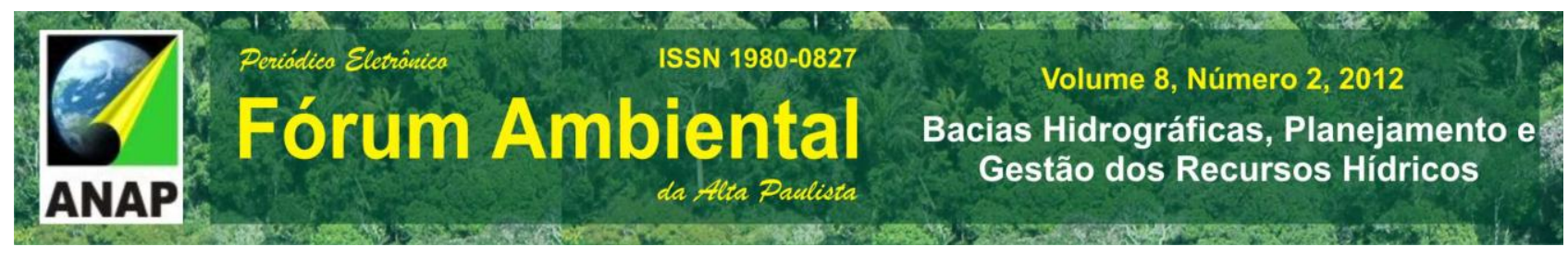

bacia. $O$ cálculo desse fator é determinado pela equação:

$$
F=\frac{A}{L^{2}}
$$

Onde: $F=$ Fator de Forma (adimensional); $A=$ Área $\left(\mathrm{km}^{2}\right) ; \mathrm{L}=$ Comprimento do eixo principal $(\mathrm{km})$; Indice de circularidade (Ic) esse índice possui uma variação de acordo com o formato da bacia. Tende para unidade em bacias circulares e diminui em bacias com formatos alongados. Segundo Andrade et al. (2008), esse índice relaciona o perímetro da bacia e a sua área. A determinação desse fator utiliza a seguinte equação:

$$
I c=\frac{12,57 \cdot A}{P^{2}}(3)
$$

Onde: Ic = índice de circularidade (admensional); $A=$ área de drenagem $\left(\mathrm{m}^{2}\right) ; \mathrm{P}=$ perímetro $(\mathrm{m})$; O parâmetro sistema de drenagem é composto pelo rio principal de uma bacia hidrográfica e por seus tributários. A determinação referente ao sistema de drenagem possibilita a deliberação sobre o maior ou menor tempo que a água demora a deixar uma bacia hidrográfica. Alguns parâmetros são fundamentais no estudo do sistema de drenagem: Ordem dos Canais, Densidade de Drenagem e Extensão média do Escoamento Superficial; O parâmetro ordem dos canais se refere a uma classificação sobre o grau de ramificações e/ou bifurcações presentes em uma bacia hidrográfica. A classificação de ordenamento dos cursos mais utilizada é a proposta por Horton (1945) e modificada por Strahler (1957); Segundo Carvalho et al. (2009), a densidade de drenagem indica a real eficiência da drenagem atuante na bacia hidrográfica. Sua determinação consiste numa relação entre o comprimento total dos cursos d'água e a área de drenagem. O parâmetro é obtido através da equação:

$$
D d=\frac{R d}{A}(4)
$$

Onde: $\mathrm{Dd}=$ é a densidade de drenagem $\left(\mathrm{km} / \mathrm{km}^{2}\right) ; \mathrm{Rd}=$ rede de drenagem $(\mathrm{km})$; $A=$ é a área da bacia (km2); Extensão média do escoamento superficial esse parâmetro relaciona a distância média que a água proveniente das precipitações, teria que escoar sobre a bacia em linha reta do ponto onde ocorreu a sua queda até o ponto mais próximo do leito de qualquer curso d'água. Para facilitar a obtenção do parâmetro, a bacia é modificada para forma de retângulo com uma mesma área, no qual, o lado maior é a soma dos comprimentos da bacia (Vilella \& Mattos, 1975). Sua obtenção é ocasionada através da equação: 


$$
l=\frac{A}{4 . L}(5)
$$

Onde: $A=$ área $\left(\mathrm{km}^{2}\right) ; \mathrm{L}=$ Comprimento do rio principal $(\mathrm{km})$.

\section{RESULTADOS E DISCUSSÃO}

Os resultados da caracterização fisiográfica realizada para o Córrego Ipê (Tabela 1), demonstram que, o valor obtido para o parâmetro lc foi de 0,55. Esse resultado demonstra que, a microbacia em estudo apresenta dificuldades em escoar a água precipitada, devido ao seu formato que tende a ser circular segundo Muller (1953) e Schumm (1956). Esses autores classificam o lc de três formas: valores < 0,51 demonstram que a bacia tende a ser mais alongada e tem como tendência 0 favorecimento do escoamento; = 0,51 demonstra um nível moderado de escoamento e valores > 0,51 apresentam forte indício de que a bacia tende a um formato circular, o que favorece os processos de enchentes.

Para o parâmetro Kc, os resultados obtidos demonstram que, a área de estudo pode ser classificada como sendo "parcialmente sujeita a enchentes", pois, o Kc obtido foi de 1,33 segundo Oliveira (1997). Por meio ainda desse parâmetro, foi possível concluir que, a microbacia tende ao formato circular, visto que, o valor obtido está próximo da unidade. De acordo com Villela \& Matos (1975) bacias hidrográficas que apresentam formatos alongados, são pouco predispostas a enchentes, pois, apresentam menores concentrações de deflúvio.

Tabela 1. Parâmetros fisiográficos determinados para a Microbacia do Córrego da Véstia

\begin{tabular}{ll}
\hline Parâmetro & Dimensões \\
\hline Área de drenagem & $20,41 \mathrm{~km}^{2}$ \\
\hline Perímetro & $24,92 \mathrm{~km}$ \\
\hline Comprimento do rio principal & $9,76 \mathrm{~km}$ \\
\hline Coeficiente de compacidade (Kc) & 1,33 \\
\hline Fator forma (Kf) & 0,26 \\
\hline
\end{tabular}




\begin{tabular}{ll}
\hline Índice de circularidade (Ic) & 0,55 \\
\hline Ordem dos canais & $4^{\mathrm{a}}$ ordem \\
Densidade de drenagem & $2,06 \mathrm{~km} / \mathrm{km}^{2}$ \\
\hline
\end{tabular}

Analisando os resultados obtidos para o $\mathrm{Kf}$, verificou-se também que a área de estudo está pouco sujeita a processos de inundação, visto que, o valor do Kf adquirido foi de 0,55. De acordo Wisler \& Brater (1964) valores baixos para esse parâmetro, comprovam que, essas bacias hidrográficas são pouco propensas aos processos de inundações quando confrontadas com bacias de mesma dimensão, que apresentem um Kf mais elevado. Segundo Vilella \& Mattos (1975), a densidade de drenagem na área de estudo foi classificada como pobre, visto que, o valor obtido foi de $2,06 \mathrm{~km} / \mathrm{km}^{2}$. Esse valor segundo os autores varia de $0,5 \mathrm{~km} / \mathrm{km}^{2}$ em bacias com uma drenagem pobre a $3,5 \mathrm{~km} / \mathrm{km}^{2}$, ou superior, em bacias consideradas bem drenadas.

O baixo resultado obtido para esse parâmetro, segundo Christofoletti (1980) classifica essa microbacia como sendo pouco suscetível a processos erosivos naturais. 0 Córrego Ipê foi enquadrado segundo a classificação de Strahler (1957) como sendo de $4^{\text {a }}$ ordem. A ordem dos canais corresponde ao grau de ramificação ou bifurcação presente em uma bacia. Esse resultado indica que a área de estudo apresenta o sistema de drenagem ramificado. Tonello et al. (2006), afirmam que, o número de ramificações abaixo de 4 é considerado trivial em pequenas bacias, e que, quanto mais elevado o índice obtido para esse fator, maior será a rede de drenagem de uma bacia.

A análise das representações da Figura 2 e da Tabela 2 mostra que a microbacia hidrográfica do Córrego do Ipê abrange uma área de preservação permanente de 385,64 há. Dentre estas somente 83,84 ha apresentam área com vegetação preservada, a grande maioria 301,8 ha encontra-se degradada sendo que destas 216,52 ha apresentam níveis parciais de degradação e 85,28 ha encontram-se totalmente degradados. 
Tabela 2. Níveis de degradação em área na Microbacia Córrego Ipê

\begin{tabular}{ll}
\hline Nível de Degradação & Área \\
\hline Vegetação conservada & 83.84 ha \\
Vegetação parcialmente degradada & 216.52 ha \\
Vegetação degradada & 85,28 ha \\
\hline
\end{tabular}

\section{AVALIAÇÃo Do NÍVEL DE DEGRADAÇÃo DAS ÁREAS DE PRESERVAÇÃo PERMANENTE} DA MICROBACIA CÓRREGOIPÊ, MUNICÍPIO DE GUARAÇAÍ-SP

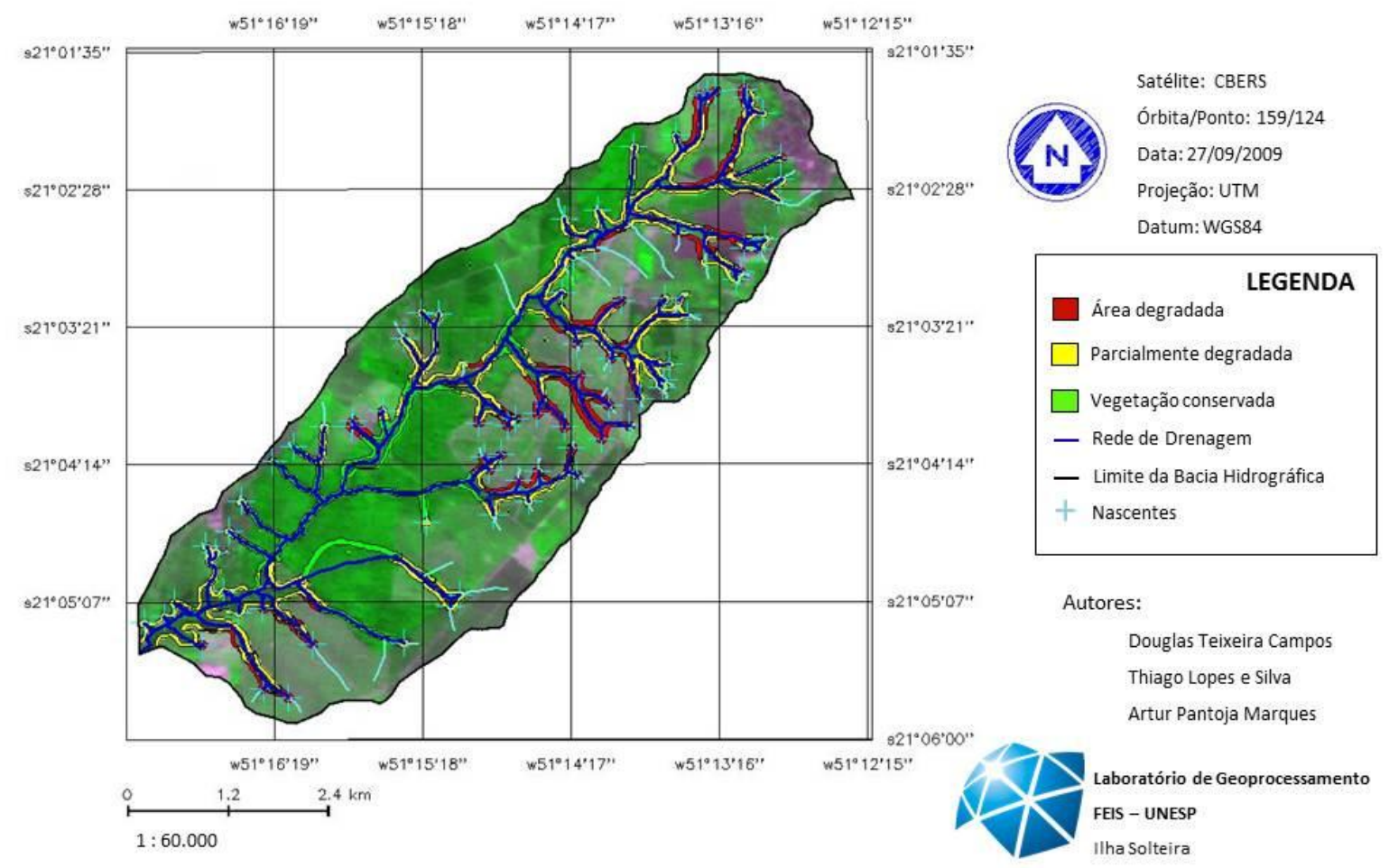

Figura 2. Ilustração da área de preservação permanente (APP) e dos níveis de degradação.

\section{CONCLUSÕES}


A análise e a caracterização fisiográfica completa da microbacia hidrográfica Córrego do Ipê incluindo análise dos níveis de degradação, delimitação das áreas de preservação permanente, foram obtidas a partir do uso de Sistema de informação geográfico que permitiu o cálculo de parâmetros morfométricos como obtenção de coeficiente de compacidade, fator forma, densidade de drenagem e Índice de circularidade, os quais foram muito importantes na determinação dos níveis de degradação da microbacia estudada.

Verificou-se que a microbacia estudada possui um formato alongado e seu declive pouco acentuado. O local é pouco propenso a inundação, portanto a degradação observada é proveniente da ação humana e do mau uso do solo, havendo deficiência em técnicas de conservação.

\section{REFERÊNCIAS}

ANDRADE, N.L.R. de; XAVIER, F.V.; ALVES, E.C.R. de F. SILVEIRA, A.; OLIVEIRA, C.U.R. de. 2008. Caracterização morfométrica e pluviométrica da bacia do Rio Manso MT. Revista Brasileira de Geociências, 27, 2, 237-248.

BIASI, M. Carta de declividade de vertentes: confecção e utilização. Geomorfologia. São Paulo. 21-8-12, 1970.

BORSATO, F. H. \& MARTONI, A. M. Estudo da fisiografia das bacias hidrográficas urbanas no Município de Maringá, Estado do Paraná. Acta Scientiarum. Human and Social Sciences. Maringá, v. 26, n. 2, p. 273-285, 2004.

CÂMARA, G.; DAVIS, C.; CASANOVA, M. A.; QUEIROZ, G. R. D. (Eds.). Bancos de dados geográficos. Curitiba: Editora MundoGEO, 2005. 
CÂMARA, G.; MEDEIROS, J. S. Monitoramento da ocupação agrícola. In: Assad, E . D.; Sano, E. E. Sistemas de informação geográfica: Aplicações na agricultura. 2 ed. Brasília. Embrapa - CPAC, 1998, Cap. 1, p. 3-11.

Carvalho, W.M. de C.; Vieira, E. de O.; Rocha, J.M.J.; Pereira, A.K. dos S.; CARMO, T.V.B. 2009. Caracterização Fisiográfica da Bacia Hidrográfica do Córrego do Malheiro, no município de Sabará - MG. Revista Irriga, 14, 3, 398-412.

CHRISTOFOLETT, A. Geomorfologia. São Paulo: Editora Edgard Blücher / EDUSP, 1980. $150 \mathrm{p}$.

CORDOVEZ, J. C. G. Geoprocessamento como ferramenta de gestão urbana. In: SIMPÓSIO REGIONAL DE GEOPROCESSAMENTO E SENSORIAMENTO REMOTO, 2002, Aracajú. Anais... Aracajú, s.n., 2002.

DURIGAN, G.; MELO, A. C. G. de; MAX, J. C. M.; VILAS BOAS, O.; CONTIÉRI, W. A. Manual para recuperação das matas ciliares do Oeste paulista. São Paulo: Instituto Florestal, 2001. 16 p.

FLORENZANO, T. G. Imagens de satélite para estudos ambientais. São Paulo: Oficina de Textos. 2002.

HORTON, R.E. 1945. Erosional development of streams and their drainage basins: hidrophysical approach to quantitative morphology. Bulletim Geologic Society of America, v.56, n. 3, p. 275-370.

MARTINS, S. V. Recuperação de matas ciliares. Viçosa: Aprenda fácil, 2001. Fonte resumida.

MORAES, R. M. Sensoriamento remoto e classificação de Imagens: apostila/1999.

MOURA, R.S. Caracterização Fisiográfica e Regionalização de Vazão na Microbacia do 
Córrego do Boi, Aparecida D’Oeste, SP. 2008. Monografia (Engenharia Agronômica). Faculdade de Engenharia do Campus de Ilha Solteira -UNESP. Ilha Solteira - SP, $48 p$.

MÜLLER, V.C. A quantitative geomorphology study of drainage basin characteristic in the Clinch Mountain Area. New York: Virginia and Tennesse. Dept. of Geology. n. 3, p. 30, 1953.

RESENDE, M.; CURI, N.; REZENDE, S. B.; CORRÊA, G. F. Pedologia: base para distinção de ambientes. Viçosa: NEPUT, 304p. 1995.

RICHARDS, J. A. Remote sensing digital image analysis. An Introduction. Berlin: Springer-Verlag Heidelberg, 1993.

RODRIGUES, M. Introdução ao geoprocessamento. Anais. Simpósio brasileiro de geoprocessamento. São Paulo: Universidade de São Paulo, 1990. p. 1-26.

RICHARDS, J. A. Remote sensing digital image analysis. An Introduction. Berlin: Springer-Verlag Heidelberg, 1993.

ROSIM, S.; PELLEGRINO, S. Extração de rede de drenagem de imagem de radar usando modelos digitais de terreno. GIS Brasil 99; 1999; 1; 1; 352; 358.

SCHUMM, S. A. Evolution of drainage systems and slopes in badlands of Perth Amboy. Geological Society of America Bulletin, n. 67, p. 597-646, 1956.

STRAHLER, A. N. 1957. Quantitative analysis of watershed geomorphology. Transaction of America Geophysics Union, v. 38. p 913-920. 1957. 
TONELLO, K. C.; DIAS, H. C. T.; SOUZA, A. L.; ALVARES, C. A.; RIBEIRO, S.; LEITE, F.

P. Morfometria da Bacia Hidrográfica da Cachoeira das Pombas, Guanhães - MG. Revista Árvore, v.30, n.5, p.849-857, 2006.

VILELLA, S. M.; MATOS, A. Hidrologia Aplicada. São Paulo: Editora McGraw-Hill, 1975. 245p.

WISLER, C. O.; BRATER, E. F. Hidrologia. Tradução e publicação de Missão NorteAmericana pela Cooperação Econômica e Técnica no Brasil. Rio de Janeiro: Ao Livro Técnico S.A. 1964. 484p. 